\title{
Fiberoptic Evaluation of Peripheral Airways of Two Patients with Acute Respiratory Failure during Mechanical Ventilation
}

\author{
Junzo Takeda, Mitsuru Tanaka*, Ryoichi OchiaI, \\ Muneaki ShImada, Eiichi KoHDA* and Kazuaki Fukushima
}

\begin{abstract}
(Key words: bronchiolectasis, fiberoptic bronchoscopy, mechanical ventilation)
\end{abstract}

Fiberoptic bronchoscopy is an useful examinations to evaluate the patient's airway in intensive care unit because this technique is relatively non-invasive and can be repeated. A conventional fiberoptic bronchoscope, however, is too large in diameter to observe the peripheral airways.

Recent technological development in fiberoptic bronchoscope has enabled us to observe more peripheral airways. To evaluate the changes and the courses of the peripheral airways of acute respiratory failure during mechanical ventilation, we observed the peripheral airways by using a fiberscope of 1.8 $\mathrm{mm}$ outer diameter (BF-1.8T; Olympus) in two patients who needed artificial ventilation due to acute respiratory failure. Patients were informed of the study before the examination.

\section{Case Report}

Case 1

Seventy years old female was admitted to our hospital for esophageal can-

Department of Anesthesiology and General $1 \mathrm{n}$. tensive Care Unit, and *Radiology, School of Medicine, Kejo University, Tokyo, Japan

Address reprint requests to Dr. Takeda: Department of Anesthesiology, School of Medicine, Keio University, 35 Shinanomachi, Shinjuku, Tokyo, 160 Japan cer. She had dysphagia and vomiting for three months prior to admission. Respiratory function test showed \%VC of $122 \%$ and FEV $_{1 \%}$ of $78 \%$. Arterial blood gas analysis was pH 7.45, $\mathrm{PaCO}_{2} 34.6$ torr, and $\mathrm{PaO}_{2} 87$ torr at room air. Chest X-ray film and other laboratory data revealed no abnormalities, except slight increase in GOT (38 IU $\left.\cdot l^{-1}\right)$ and GPT (51 IU $\left.\cdot l^{-1}\right)$. She had a history of hypertension and antihypertensive drugs were prescribed for five years.

After the esophagectomy, she could not weaned from mechanical ventilatory support due to hypoxia with bilateral pleural effusion. On ninth postopcrative day, chest $\mathrm{X}$-ray film showed perivascular cuffings, obliteration of left hemidiaphragma, and consolidative density behind the heart. $\mathrm{PaO}_{2}$ was 108 torr at $\mathrm{FI}_{\mathrm{O}_{2}} 0.6$ and $8 \mathrm{cmH}_{2} \mathrm{O}$ of PEEP.

In order to prevent hypoxia during bronchoscopy, the patient was ventilated pure oxygen. The bronchoscope was inserted via a Swivel connector (Swivel Y; Sontek Medical Inc.), between the ventilator cuircuit and the endotrachcal tube. Disconnecting the ventilator or changing the ventilator settings was not required. Oxygen saturation was monitored by a pulse 


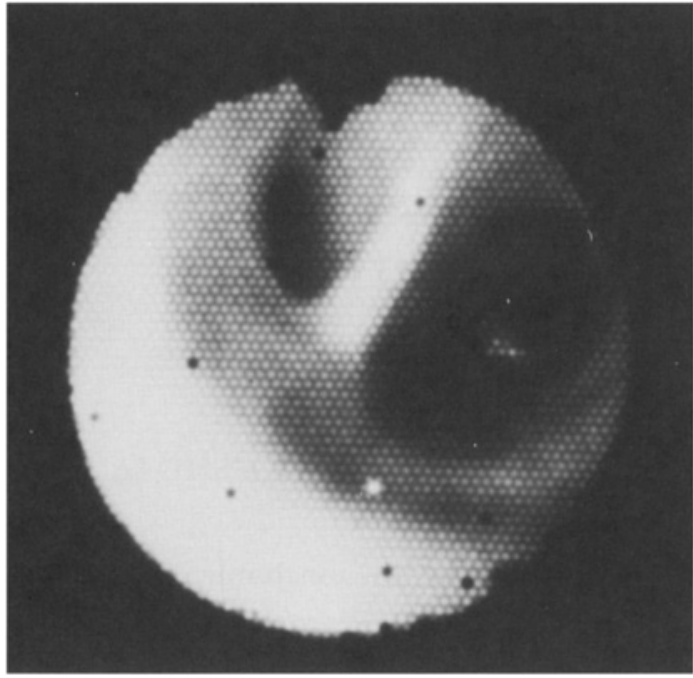

Fig. 1. Peripheral airway picture of fiberscopy by the BF-1.8T at 9th day of the mechanical ventilation of the case 1 . Chest $\mathrm{X}$-ray film showed perivascular cuffings, oblitcration of left hemidiaphragma and consolidative density behind the heart. Fiberscopy revealed mild secretion and pigmentation, but no ectasis and pallor.

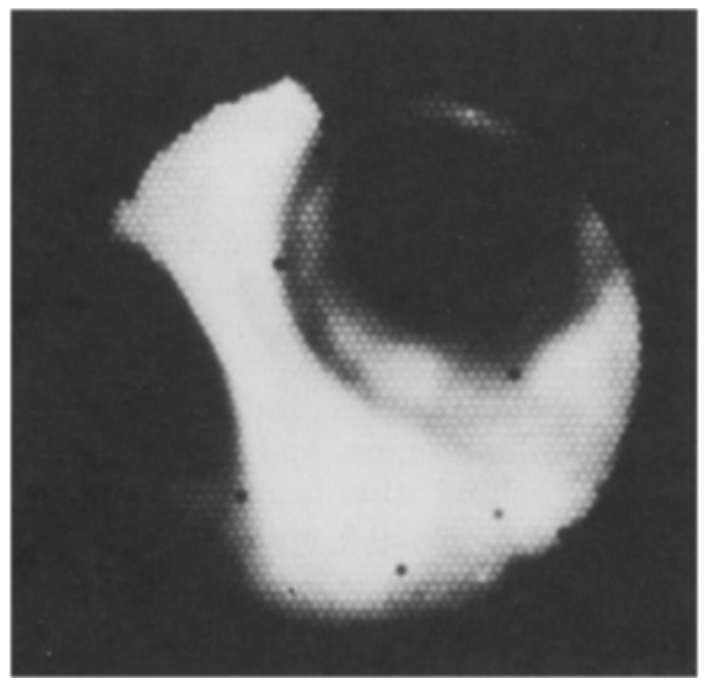

Fig. 2. Fiberscopy at 16th day of the mechanical ventilation of the case 1 . Although there was a clearing of perivascular cuffings on chest X-ray film, ectasis and mild pallor were identified in fibcrscopy.

oxymeter throughout bronchoscopy.

Examination of peripheral airways

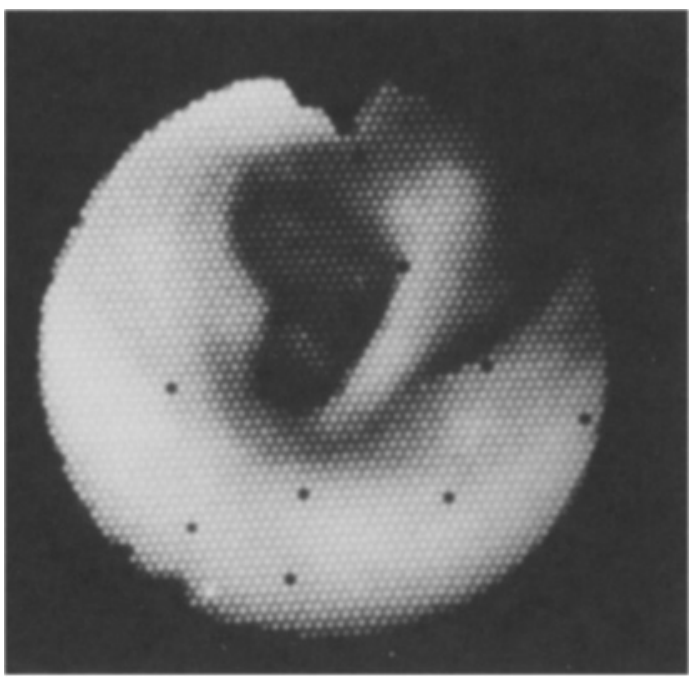

Fig. 3. Fiberscopy at 23 th day of the mechanical ventilation of the case 1 . Chest $\mathrm{X}$-ray film showed a hyperlucency of bilateral upper lobes but did not demonstrated remarkable changes. Ectasis and pallor developed and secretion, stenosis and swelling were found in the peripheral airways

by the BF-1.8T showed mild secretion and pigmentation (fig. 1). One week later, 16th postoperative day, ectasis and mild pale changes as well as pigmentation of peripheral airway wall were identified by fiberscopy (fig. 2) in spite of improvement on the chest $\mathrm{X}$-ray film. On 23th day, $\mathrm{Pa}_{2}$ was improved to 97 torr with $\mathrm{FI}_{\mathrm{I}_{2}} 0.45$ and $4 \mathrm{cmH}_{2} \mathrm{O}$ of PEEP. Chest X-ray film demonstrated no changes except a hyperlucency of bilateral upper lobe compared with that on 16th day. However, ectasis and pallor in peripheral airways became prominent, and stenosis and secretion were also found sporadically (fig. 3). Two days later she was successfully weaned from ventilator.

\section{Case 2}

Sixty eight years old man, who had no history of respiratory disease, underwent right maxillectomy due to the maxillary cancer. On second postoperative day, he developed hypoxia $\left(\mathrm{PaO}_{2}\right.$ 
58.6 torr at $\mathrm{Fr}_{\mathrm{O}_{2}} 0.5$ ) and revealed bilateral diffuse infiltrative densities on chest X-ray film, possibly due to aspiration of bloody secretion from surgical wound. His lung was mechanically ventilated with $\mathrm{FI}_{\mathrm{O}_{2}}$ 0.6, tidal volume $500 \mathrm{ml}$, IMV 5/min, and PEEP 5 $\mathrm{cmH}_{2} \mathrm{O}$. One week later, diffuse abnormal shadow became worse at bilateral middle and lower lung fields with fever up to $39^{\circ} \mathrm{C}$. Arterial blood gas analysis showed $\mathrm{Pa}_{2} 90$ torr and $\mathrm{PaCO}_{2}$ 45.7 torr, when the ventilator setting was $\mathrm{FIO}_{2} 0.6$ and tidal volume $600 \mathrm{ml}$ with $5 \mathrm{cmH}_{2} \mathrm{O}$ of PEEP. Bronchoscopy by the BF-1.8T, which was performed in the same manner of Case 1, showed rnild ectasis of peripheral airway wall and pallor of mucosa. Two weeks after the initiation of mechanical ventilation, chest X-ray film showed significant improvement in the lung lesion. $\mathrm{FI}_{\mathrm{O}_{2}}$ was reduced to 0.5, and $\mathrm{Pa}_{2}$ increased to 148 torr. However, dilatation and pallor of peripheral airways became more prominent in comparison with the initial findings. On 18th postoperative day, he was successfully weaned from artificial ventilation.

\section{Discussion}

Details and characteristic features of fiberscope of the BF-1.8T which was used for observation of the peripheral airways have been described elsewhere ${ }^{1}$. Briefly, outer diameter of the fiberscope is $1.8 \mathrm{~mm}$, which enables observation of bronchi $2 \mathrm{~mm}$ or less in diameter. It cannot change the direction actively and aspirate secretion because it does not have a direction control device and a suction channel. Clinical usefulness of the BF1.8T has been reported by Tanaka and colleagues in patients with chronic lung diseases $^{2}$.

Although we inserted the fiberscope blindly, we confirmed by the chest $\mathrm{X}$ ray films and computed tomographies that tip of the BF-1.8T fiberscope was located in the right lower lobe and close to the diaphragmatic pleura in most cases. Tanaka and his colleagues ${ }^{1}$ described that the BF-1.8T could reach to the tenth to thirteenth generation of bronchial dichotomy.

Pigmentation, ectasis and pale color change of peripheral airways were observed by fiberscopy during mechanical ventilation. Pigmentation, which is a characteristic feature in peripheral airways, was reported to represent submucosal deposition of inhaled substances ${ }^{2}$. Peripheral airways exhibited an accordion pattern of smooth muscles which was similar in central airways, despite of no cartilage rings. Change in this structure of the mucosal surface associated with dilatation was classified as ectasis in peripheral airway lesions ${ }^{2}$. Slavin and $\mathrm{Nunn}^{3}$ described that the degree of bronchiolectasis was correlated well with the period and/or magnitude of artificial ventilation and PEEP level from the study at autopsy. No clinical study has been conducted to clarify the morphological changes in peripheral airways. Ectasis and pallor became prominent during long mechanical ventilation in this study, even if patient's oxygenation and the chest $\mathrm{X}$-ray findings improved. Ectasis in this study is mostly likely barotrauma in periphcral airways by mechanical ventilation. Pallor of bronchi wall suggests ischemia of mucosa, which may be caused by disturbance of microcirculation from the pulmonary or the bronchial circulation. Clarification of these relationship must need further studies.

Morphological changes in peripheral airways of two patients who were on mechanical ventilation due to acute respiratory failure were studied by using the fiberoptic bronchoscope of 1.8 mm outer diameter. Dilatation and pallor of the peripheral bronchial wall were important main findings which became more prominent in relation 
with the period of mechanical ventilation. These changes, however, were not related with the chest X-ray findings or the arterial oxygenation. This study suggests that the clinical findings during mechanical ventilation do not reflect the pathological changes in peripheral airways. It gives us some warnings when positive pressure ventilation is applied for the patients.

(Received Aug. 15, 1991, accepted for publication Oct. 2, 1991)

\section{References}

1. Tanaka M, Satoh M, Kawanami $O$, et al: A new bronchofiberscope for the study of diseases of very peripheral airways. Chest 85:590-594, 1984

2. Tanaka M, Kawanami O, Satoh M, et al: Endoscopic observation of peripheral airway lesions. Chest 93:228-233, 1988

3. Slavin G, Numn JF, Crow J, et al: Bronchiolectasis - a complication of artificial ventilation. $\mathrm{Br}$ Med J 285:931-934, 1982 